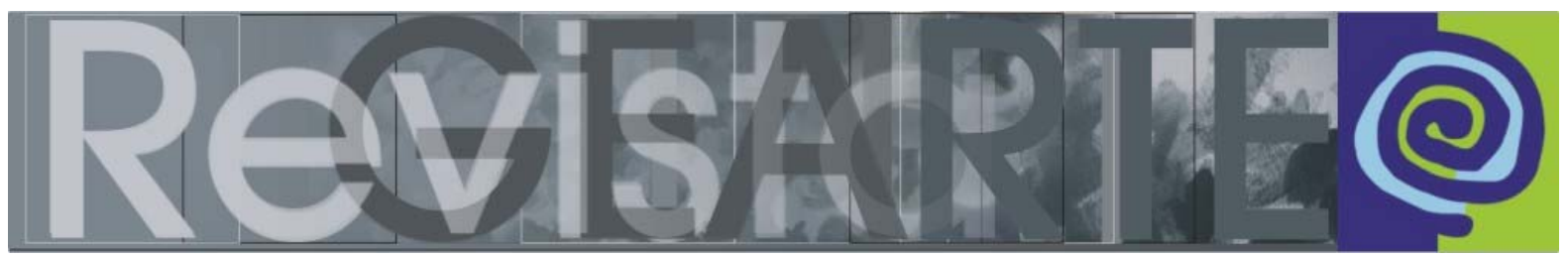

ISSN 2357-9854

\title{
A publicidade como arte e cultura, e não por acaso
}

\author{
Paula Mastroberti (UFRGS - Brasil)
}

\begin{abstract}
RESUMO
Este artigo discute, a partir do seu título, um pensar educador que, apoiado nos Estudos Culturais Visuais, amarra-se a uma visão adorniana que opõe a indústria e o consumo cultural à experiência da arte. Reflito, assim, sobre as questões surgidas em minhas aulas no Curso de Licenciatura em Artes Visuais acerca do modo como abraçamos, irrefletidamente, certas pedagogias desviadas do sentido primeiro dos estudos culturais midiáticos (como prefiro) - 0 de diluir as fronteiras entre os diferentes sistemas artísticos culturais, democratizando e ampliando o conceito de arte. Tais desvios ocorrem na apropriação dos objetos culturais midiáticos ora como escada para aperfeiçoamento do conhecimento da "verdadeira arte", ora como prejudicadores à formação estética e psicológica de crianças e adolescentes. Ao tomar por temas a publicidade como arte e o consumo conspícuo como lazer cultural defendo uma educação do sujeito empoderado para a cultura e a arte em todas as suas instâncias.
\end{abstract}

PALAVRAS-CHAVE

Arte e publicidade. Publicidade e educação. Cultura midiática e educação. Cultura visual e publicidade. Cultura visual e educação.

\section{ABSTRACT}

This article discusses, from its title, a pedagogic thinking, besides being supported by visual cultural studies, its tied up to an Adornian vision that opposes industry and cultural consumption to the experience of art. It reflects as well on the issues raised in my classes into the Course of Graduation in Visual Arts about how we unthinkingly embrace some pedagogies which has diverted of primary aim of media cultural studies (as l'd rather to name) - the blur the boundaries between the different cultural/artistic systems, democratizing and expanding the concept of art. Such deviations occur when we ownership media cultural objects either as steps to improve the knowledge of the "fine art", or as enemies of the aesthetic and psychological development of children and adolescents. By taking on issues such as advertising as art and conspicuous consumption as a cultural leisure, I advocate an education of the subject empowered to culture and art in all its instances.

\section{KEYWORDS}

Art and advertising. Advertising and education. Media culture and education. Visual culture and advertising. Visual culture and education.

\section{Os nossos comerciais}

Do interior do Curso de Licenciatura em Artes Visuais, ministro uma disciplina voltada para a educação infantil. Trata-se de um percurso muito prazeroso para mim, repetido a cada semestre. Essa disciplina apoia-se, conforme eu a organizei, num tripé apoiado nos seguintes objetos - infância, arte, educação - entrecruzados pelos respectivos contextos históricos e socioculturais. Cada abordagem alterna desconstrução e reconstrução de 
conceitos, desenvolvida a partir de uma metodologia sistematizada em uma narrativa cujo incipit implica uma desestabilização episódica, geradora de uma busca, e cujo excipit, espera-se, seja a bem sucedida figuração de um novo conhecimento ou reconfiguração de um conhecimento anterior.

Um dos seus momentos mais ricos - e polêmicos - é aquele em que tratamos da cultura midiática para a infância. Digo cultura midiática, em detrimento de cultura visual, pelo mesmo motivo que me custa restringir as artes visuais ao sentido do olhar ${ }^{1}$. Meu percurso de pesquisadora me inclina a favor dos estudos estadunidenses protagonizados por William Mitchell e Mark Hansen, defensores de um conceito de mídia mais amplo, em que as artes, sistemas semióticos e culturas são relacionados com maior equidade. Assim, mídia "nomeia uma forma técnica ou técnicas formais ou, de fato, toda uma midialidade que é constitutiva do humano como uma forma 'biotécnica' de vida."2 (MITCHELL; HANSEN, 2010.).

O assunto excita os alunos não apenas em virtude do imaginário que é retomado através de lembranças de todo um universo ligado aos objetos midiáticos destinados à infância - livros, filmes, desenhos animados e brinquedos, etc - , mas também em decorrência da conhecida Resolução 163 aplicada pelo CONANDA (Conselho Nacional dos Direitos da Criança e do Adolescente) à publicidade voltada para o consumidor infantil ${ }^{3}$. Jogando com elementos do imaginário emoafetivo e, ao mesmo tempo, estimulando o pensamento crítico, procuro fazer com que os alunos reflitam sobre essa

\footnotetext{
1 Já referido em meu artigo $O$ livro como objeto predisposto à interdisciplinaridade, publicado na Revista GEARTE, v. 1, n. 2, p.167-181, 2014.

2 "[...] names a technical form or formal technics, indeed a general mediality that is constitutive of the human as a 'biotechnical' form of life." (MITCHELL; HANSEN, 2010, p. 38. Tradução livre.) O termo 'media', em inglês, nem sempre é traduzido de forma correta em português, no plural. Mídia, substantivo singular, em inglês é medium, do qual media seria o seu plural, traduzido como 'mídias' ou, dependendo do caso, 'meio'.

\begin{abstract}
${ }^{3}$ A Resolução 163, publicada em 13 de março de 2014, considera abusiva toda publicidade que faz uso dos seguintes recursos: I) linguagem infantil, efeitos especiais e excesso de cores; II) trilhas sonoras de músicas infantis ou cantadas por vozes de criança; III) representação de criança; IV) pessoas ou celebridades com apelo ao público infantil; V) personagens ou apresentadores infantis; VI) desenho animado ou de animação; VII) bonecos ou similares; VIII) promoção com distribuição de prêmios ou de brindes colecionáveis ou com apelos ao público infantil; e IX) promoção com competições ou jogos com apelo ao público infantil.
\end{abstract}


regulamentação, apoiados na leitura de excertos de Raimundo Martins (2008), Jurandir Freire Costa (2005) e Gisela Taschner (2009). Exibo alguns comerciais famosos e premiados que, desde a década de 1980, vêm se dirigindo à criança direta ou indiretamente: Aquarela, da Faber-Castell, uma animação de 1983 com trilha sonora da conhecida música de Toquinho entoada por uma voz infantil4; Mamíferos, da Parmalat, cuja coreografia performatizada por bebês-filhotes encantou o público, a partir de 19965; e Isso Muda o Mundo, do Banco Itaú, conjunto de peças publicitárias criadas, em 2013 , com o propósito de divulgar as relações da marca com as artes, a educação e a cultura ${ }^{6}$.

Se tomarmos a lista de recursos proibidos pela Resolução 163 (ver nota de rodapé $n .3)$, nenhuma dessas peças passaria pelo CONANDA; nem mesmo a altruísta campanha do Banco Itaú, cuja principal acionista individual é Ana Lúcia de Mattos Barretto Villela, fundadora do Instituto Alana, órgão cuja pressão motivou a criação dessa Resolução. A mesma instituição - um braço brasileiro da estadunidense Alana Foundation -, financiou, entre outros projetos desenvolvidos em prol do bem-estar da criança, documentários como A criança é a alma do negócio, que trata do consumo infantil (RENNER, 2008).

Ao esclarecer a inegável e histórica cumplicidade entre o sistema econômico - indústria, mercado, publicidade e consumo - e os sistemas da arte e da educação, provoco imediatamente uma situação de desconforto entre os meus alunos licenciandos. Afinal, nossos produtos - a poética e o ensino são medidos em valores prioritariamente espirituais ou simbólicos (BOURDIEU, 2011) e verbos como vender e comprar ou substantivos como mercadoria e consumo não devem emergir em nosso jargão decantado de signos materiais. Assim, quando vêm à tona, acabam arrastando consigo todo um léxico denotativo de culpa e de negatividade.

Dentro disso, os discursos sobre a infância e suas relações com a cultura de entretenimento industrial ainda são moldados em fôrmas antigas e

\footnotetext{
${ }^{4}$ Agência FCB, por Cristina Carvalho Pinto, com animação da Start Anima.

${ }^{5}$ Agência DM9DDB, com direção de Erh Ray e Nizan Guanaes.

${ }^{6}$ Agência África, por Paulo Medeiros e Viviane Araújo, entre outros.
} 
românticas, reprodutoras de uma imagem infantil pura e inocente, sem levar em conta as transformações ocorridas não só no que se diz sobre a criança, mas também na sua realidade interacional com o mundo dos adultos. Assim, binômios como criança e mercado, criança e consumo, sempre que discutidos pelo viés pedagógico e pelas políticas educacionais, ainda pressupõem uma criança apática, incapaz de falar (in-fantia), de pensar, decidir e expressar-se de modo crítico. Essa imagem deriva de um complexo teórico ultrapassado que entendia também o adulto como um consumidor passivo, cuja mente estaria sujeita à lavagem pelo discurso publicitário.

Ao tomar a arte publicitária e o consumo conspícuo ${ }^{7}$ como objetos de reflexão com finalidade de incluí-los no ensino contemporâneo de artes - este que se diz norteado pelos estudos culturais "visuais" - ergo uma voz crítica e reflexiva sobre as pedagogias envolvidas com a mediação da cultura midiática relacionada à infância, seja com intuito de vilanizá-la, apontando aspectos exclusivamente seviciantes e rechaçando o seu valor cultural, simbólico e estético; seja para demonizá-la, isto é, dispondo dela apenas como um mediador $^{8}$ entre os valores materiais apegados ao consumo sensual e os valores supostamente espirituais da grande arte. Essa posição simplista e dicotomizante, apontada por Paula Sibilia (2013) como parte da síndrome que caracteriza a crise do ensino escolar, precisa ser melhor avaliada. Está claro que os manifestos pedagógicos a favor da proibição de anúncios publicitários dirigidos ao público infantil, no sentido de resguardar sua inocência, apontam a uma incapacidade de reconhecer a criança contemporânea como potencial prossumidora ou produsuária (SIBILIA, 2013). Entendê-las como consumidoras inseridas na sociocultura em rede significa entendê-las inseridas no regime do capitalismo artista (LIPOVETSKY; SERROY, 2013), em que as fronteiras entre

\footnotetext{
${ }^{7}$ Estabelecido por Thorsten Verbein, o termo consumo conspícuo será retomado por Gisela Taschner (2009) para determinar uma forma de consumo cujos fins são simbólicos ou lúdicos, seja para agregar ao consumidor um dado status sociocultural ou para o seu lazer.

${ }^{8}$ Os termos demoníaco e mediador têm afinidade na medida em que tomo demoníaco em sua acepção primeira, a de entidade mediadora entre aqueles que habitam a terra (matéria) e as deidades celestes (espírito), ou seja, entre os homens e os deuses. O mediador é, de modo semelhante, aquele que media (como a mídia) ou faz trafegar, signos, dados, conhecimentos, compartilhando-os ou disseminando-os numa dada comunidade (discente ou outra).
} 
as diversas artes, o design e a publicidade, entre outros, encontram-se diluídas e cujos produtores não disfarçam mais seus vínculos com o mercado.

\section{Comprando e vendendo arte e educação}

As relações entre a arte e o mercado não são novidade e constam, ainda que eventualmente desfocadas, ao longo da bibliografia da sua história e de sua crítica ${ }^{9}$. Há comprovação de sobra de que a arte sempre dependeu ou pôs-se a serviço da consagração de reis, do poder econômico ou religioso e de diversas ideologias socioculturais e políticas. Mesmo em seus períodos mais rebeldes, a obra artística acaba representando ou atribuindo algum status social ao seu proprietário, além de contribuir para divulgar e promover sujeitos e ideias. A ela também agrega-se um valor capital, ou seja, um valor de compra e de venda, sem que isso a menorize em suas qualidades poéticas.

O desenvolvimento industrial e a mecanização criaram a produção em larga escala e também novos espaços de trabalho para o artista: o design e, indiretamente a princípio, a publicidade e a propaganda ${ }^{10}$. Todo objeto industrial deriva de uma autoria ou princípio criativo conceitual - o mictório, antes de ser apropriado por Duchamp, foi idealizado por um projetista cujo conceito deve combinar prazer estético e funcionalidade. Diferente do artesão ou do ourives de épocas anteriores, o artista industrial concebe um objeto, mas não o executa. Porém, à semelhança de muitos pintores, gravadores ou escultores, cujos ateliers cooptavam aprendizes para atender às inúmeras encomendas, ou dos adeptos às correntes conceituais da arte a partir da década de 1950, esse profissional conta com a fábrica e seus operários para atender ao aumento das demandas provocadas pelo surgimento dos grandes centros urbanos - cujo número de habitantes supera o dos antigos burgos.

\footnotetext{
${ }^{9}$ Embora carecendo de revisão e de novos olhares, é preciso citar Arnold Hauser (1982) como o principal esforço nesse sentido.

${ }^{10}$ No jargão da Comunicação, publicidade e propaganda diferem quanto aos seus princípios retóricos: a propaganda vale-se de uma retórica totalizante, cujo discurso não leva em consideração os interesses do público e a publicidade, ao contrário, estabelece uma comunicação afetiva e interativa com seu público-alvo, procurando ser sensível aos seus desejos. (MARANHÃO, 1988).
} 
Numa comunidade pequena, persuadir ou convencer um comprador da qualidade de um artefato se resolve na barraca da feira ou na porta da casa; numa metrópole, a informação sobre os produtos terá que ser ampla, rápida e feita de modo a causar impacto, para destacá-los em meio as tantas outras atrações urbanas. Walter Benjamin (2009) não se cansará de falar sobre as vitrines de Paris, iluminadas pela luz elétrica recém popularizada, e sobre os cartazes que tonalizarão, com suas cores litogravadas, os austeros muros das cidades europeias e o interior dos primeiros bondes, na virada para o século $X X$. Seu imaginário de infância, evocado nos belos textos de Infância berlinense: 1900 (BENJAMIN, 2013), é povoado por esta paisagem transfigurada pela indústria e pelas novas tecnologias. O crescimento do design e da publicidade e a suas contribuições para com a formação do imaginário poético das sociedades industriais e pós-industriais é apontada em detalhes por Gilles Lipovetsky e Jean Serroy (2013). Os mesmos autores irão apontar o inegável envolvimento entre a grande arte e o mercado capital, culminando na era do "capitalismo artista".

Tanto no interior do estúdio ou atelier, como nos espaços de consagração institucionais da arte, as fronteiras entre as diversas instâncias criativas vão sendo, aos poucos, diluídas. Profissionais como Toulose Lautrec passavam, na virada do século XIX para o século XX, da pintura sobre tela ao cartaz de cabaré com o mesmo empenho. Correntes estilísticas como o arts and crafts ou 0 streamline style, fundação de escolas desde a Staatliches-Bauhaus (pouco mencionada pelos textos tradicionais de história da arte) até o Institut d'Esthetique Industriale, na França, tinham por ideologia subjascente uma arte acessível a todos, popularizada através da indústria.

Os artefatos planejados por essas escolas visavam, pois, a reprodução em série e a sua mercantilização. As escolas de design da era industrial também preparavam o artista para o incipiente mercado publicitário, na medida em que formavam para a produção de embalagens e de cartazes. A partir das décadas de 1950 e 1960, porém, já podemos falar em uma formação independente do 
publicitário $^{11}$ e da valorização artística de seus trabalhos, através de premiações e exposições em museus e espaços culturais de todo o mundo ${ }^{12}$.

Lipovetsky e Serroy defendem a ideia de que a publicidade, ao lado do design, da moda, do cinema e demais instâncias da cultura de consumo e de entretenimento, são expressões da arte na medida em que contribuem com o aumento da poeticidade dos bens de consumo; retirada a embaçada lente adorniana, que culpa a industrialização por um suposto empobrecimento do imaginário social, ambos os autores permitem visualizar as artes de compra e consumo como os maiores contribuidores para com o imaginário poético das sociedades modernas e contemporâneas:

\begin{abstract}
$\mathrm{Na}$ verdade, o reclame não veio compensar nenhuma perda, nem preencher nenhuma lacuna imaginária: ele começou a artealizar, a poetizar os bens de consumo de massa. [...] Desse ponto de vista, o desenvolvimento da publicidade moderna não traduz em absoluto um empobrecimento do imaginário, mas o advento de mercadorias mais impregnadas de dimensões simbólicas, de significados imaginários multiplicados; (LIPOVETSKY; SERROY, 2013, p. 218-219)
\end{abstract}

Era de se esperar que este modelo democrático, profundamente investigativo e conceitual (tendo em vista toda a produção teórica que gerou), repercutisse na educação básica das artes em todo o mundo. Mas não foi isso o que aconteceu.

O ensino de artes, como gosto de apontar aos meus alunos, prosseguiu dicotomizando o campo das plásticas em belas-artes e artes de ofício: enquanto as primeiras eram ensinadas aos jovens da elite, as segundas eram destinadas aos filhos do proletariado. O Brasil é um caso exemplar desse processo que aqui iniciou com a entrada da Missão Francesa e adentrou o século $X X$ com a introdução da pedagogia do livre-fazer, claramente influenciada pela estética modernista, voltada para as classes abastadas. Assim, as artes gráficas e o design industrial (de onde advirá o artista publicitário) acabaram negligenciados como área de investigação educacional, vistos como um "atraso" cultural e

\footnotetext{
${ }^{11}$ No Brasil, temos, em 1951, a Escola de Propaganda de São Paulo, fundada por Rodolfo Lima Martensen.

12 Cito, entre outras: na França, em 1978, inaugura-se o Museu da Publicidade; nos Estados Unidos, o Museu de Arte Moderna organiza uma retrospectiva de filmes publicitários em 1985.
} 
estético, senão pior: como uma arte prostituída, ao escancarar seu vínculo com a economia de mercado. O ensino de artes lutou, até o final do século $X X$, para extirpá-las dos programas curriculares baseado na ideia da inferioridade artística dos seus conteúdos, contribuindo para com a sectarização da cultura em alta (destinada às elites) e baixa (destinadas às "massas"). Na verdade, a ideia de "inferioridade" das artes e ofícios deveu-se muito mais à falta de profundidade das metodologias para a formação profissional, limitadas à repetição de fórmulas e sem nenhuma reflexão estética e conceitual.

O ensino de artes na universidade seguiu o mesmo modelo: adaptado ou não às questões das vanguardas modernistas, restringiu-se a discutir e promover a "grande arte", enquanto as artes gráficas - e, por muito tempo, também o design —foram relegados aos domínios da comunicação e da sociologia da cultura. Só a partir da década de 1960, institutos e escolas de nível acadêmico reestabeleceram o design como objeto de interesse em nível superior, pelo menos no Brasili ${ }^{13}$. Da mesma forma, em níveis teóricos, a discussão sobre a validade do design e da publicidade como arte teve início em nosso país somente a partir dos anos 1980, com a revisão de uma teoria da estética frankfurtiana a partir da ótica chamada "pós-modernista" e de suas discussões centradas no kitsch e na paródia, ou pastiche. É quando, em 1988, surgiram argumentos como os de Jorge Maranhão:

Quando dizemos que um objeto industrial não pode ser obra de arte, o dizemos na conviç̧ão de que esta não é a sua pretensão, na medida em que a noção mesma de "obra de arte" está comprometida com estéticas que se alienaram da própria sociedade industrial e, de certo modo, de seu próprio tempo. Por outro lado, temos fortes razões para não descartar a hipótese de que, em não sendo obra, contenha o que de arte pode se compreender como estético, ou produto intencional da experiência estética humana. (MARANHÃO, 1988, p. 127. Grifo do autor).

A essas questões sobreponho uma imagem de um ensino básico que pouco ou nada se compromete com uma educação da economia e das relações

\footnotetext{
${ }^{13}$ A primeira instituição de nível superior de design do país foi a ESDI - Escola Superior de Desenho Industrial - fundada em 1963 a partir de um decreto do então governador do Rio de Janeiro, Carlos Lacerda. No Brasil, como se percebe, o design como área de conhecimento superior ocorreu posteriormente ao reconhecimento da publicidade, na contramão da Europa e dos Estados Unidos, por motivos que não cabe aprofundar nesse artigo.
} 
de mercado, mas cujo ideal é fazer trafegar exclusivamente valores éticos, intelectuais, espirituais ou simbólicos. Da qual deduzimos que, ao tomar por assunto a arte, a educação não pode, de forma alguma, relacioná-la às instâncias do mercado e do consumo, mas deve, isto sim, promovê-la com base no ultrapassado espírito romântico-burguês, de sua pura sacralidade.

Não é à toa que, de todas as disciplinas, é nas artes que as diretrizes político-pedagógicas depositam as maiores esperanças para a formação da criança-cidadã igualmente idealizada. Também não é à toa que, ao evitar discutir os vínculos da arte com o pragmatismo profissional e seus contextos econômicos, tanto os conteúdos artísticos quanto os docentes da área sejam os menos considerados na hora do planejamento de projetos e planos de ensino, como denuncia Ana Luiza Ruschel Nunes em sua obra Trabalho, arte e educação (NUNES, 2004). Assim, paradoxalmente, embora as artes sejam enaltecidas pelos programas curriculares como área humanizadora por excelência, a realidade do trabalho escolar reduz a imagem da disciplina a um conhecimento fútil para a formação discente.

Torna-se compreensível, portanto, o motivo pelo qual a pedagogia da arte, ao tomar a cultura midiática como objeto, o faz pelo viés negativo facilmente perceptível em muitas de suas publicações. Fundamentada numa episteme de origem claramente frankfurtiana, essa pedagogia vincula-se a uma narrativa ideologicamente comprometida com as elites econômicas e culturais, as quais, como vêm apontando Arnold Hauser (1982), Terry Eagleton (1993) e, mais recentemente, Johanna Drucker (2010), exercem, através da promoção, da compra e da venda de seus artefatos, um papel definidor de um conceito de arte.

Com a valorização paulatina do design e da publicidade como áreas de criação, de pesquisa e de ensino acadêmico, apoiadas numa episteme que desconstrói as hierarquias entre a cultura dita popular e a erudita, a dicotomia implícita e persistente em alguns discursos pedagógicos já não faz mais sentido. Trata-se, então, de reconhecer o papel da cultura midiática — na qual se inserem o design e a publicidade - na composição de um sistema de arte compreendido como plural, tanto em sentido poético e semiótico quanto nos contextos de 
produção, veiculação e consumo, e de incluí-la como objeto de uma educação da qual requisita-se um olhar crítico. Assim, concordo com Raimundo Martins, quando diz:

A cultura visual desafia e desloca as fronteiras do sistema das belas artes e, em decorrência, gera tensões e divergências que perturbam visões curriculares violando a estabilidade acadêmica e institucional. Ao pesquisar e estudar o caráter mutante das imagens e dos objetos artísticos analisando-os como artefatos sociais, a cultura visual busca ajudar aos indivíduos, mas especialmente, aos alunos, a construir um olhar crítico em relação ao poder das imagens, auxiliando-os a desenvolver um sentido de responsabilidade diante das liberdades decorrentes desse poder. (MARTINS, 2008, p. 32).

Por outro lado, sou também obrigada a considerar as palavras de Jorge Maranhão, quando coloca, em defesa da publicidade como arte:

Independente do conteúdo estético de um determinado objeto, em algum momento ele poderá desempenhar uma função mercantil, mas certamente sempre desempenha uma função econômica e, ao contrário, independente do valor mercantil cotado para um determinado objeto, seja bem de consumo ou bem de investimento (...), nada nos leva a crer que ele seja desprovido, aprioristicamente, do seu valor estético. Seria até mesmo impossível uma separação entre arte ("pura") e mercadoria. [...] Assim como a arte questiona sua tradição monotípica e reage contra o estereótipo - e nesta reação está sua possibilidade estética - a possibilidade crítica da propaganda também reside nesta mesma ruptura criativa. (MARANHÃO, 1988, p. 112-118, passim).

Maranhão sustenta sua posição com base na retórica da propaganda, exigente de uma abordagem específica para seu estudo, atendendo às suas especificidades enquanto objeto estético. O que ele chama de arte publicitária é aquela que "[...] se consome no mercado, e que, com ele, some, como qualquer outra arte da sociedade de consumo, [...] não se resolvendo em obra, mas em arte na dimensão da efemeridade contemporânea." (MARANHÃO, 1988, 165).

Da mesma forma, ele defende a sua qualidade crítica e seu valor cultural, nas seguintes colocações:

[...] a publicidade é crítica quando recupera o ideal da profissão do publicitário, profissão no sentido etimológico e clássico do termo aquilo que se assume publicamente diante da comunidade, como ofício que serve a ela, com identidade social própria e cidadania com todos os direitos e responsabilidades, principalmente o direito à reflexão sobre o seu ser e seu fazer profissionais. (MARANHÃO, 1988, p. 170). 
E ainda:

A publicidade consciente crítica, que absorve ela mesma no seu próprio fazer a reação que a sociedade tem dela mesma, esta publicidade produz e reproduz cultura, contribui para a cultura com campanhas de grande repercussão, é uma publicidade verdadeiramente artística. (MARANHÃO, 1988, p. 172).

Ao convocar, ao lado de Lipovetsky e Serroy, o nome de Maranhão para defender o potencial estético e artístico da publicidade, não quero dizer — como ele também não diz - que toda publicidade é arte. Ao escolher três peças publicitárias bem sucedidas para exibir aos meus alunos - duas delas presentes na memória cultural e afetiva brasileira e uma ainda recente e complexa, pois alinha claramente valores culturais e pedagógicos à marca de um banco - procuro estabelecer a discussão nos seus níveis poéticos e semióticos, independente do produto que vendem. Embora seja difícil essa compreensão - uma vez que se trata de uma abordagem nova nas Artes Visuais ainda que no seio da Comunicação ela ocorra desde os anos 1980 -, aos poucos, desconstruindo preconceitos, comprova-se, em sala de aula, uma mudança de olhar com respeito aos efeitos da publicidade e da cultura midiática no imaginário infantil, para além de indutor do mero comprismo.

Após a etapa de desconstrução, é possível reconhecer, ao suspender por um momento a função primeira da peça publicitária - comunicar e seduzir para o consumo - o lirismo da animação plasticamente conduzida pela música de Toquinho para divulgar a caixa de lápis de cor da Faber Castell; os valores estéticos da campanha da Parmalat, em que a associação visual da figura e da gestualidade do corpo infantil humano às dos filhotes mamíferos exerce sobre nós um efeito afetivo carinhoso e divertido que se sobressai à marca divulgada, principalmente porque a peça preocupa-se em evidenciar o caráter lúdico que envolveu sua produção e a alegria espontânea com que os bebês portam suas fantasias e bebem leite. Da mesma forma, o roteiro, os conceitos e a qualidade visual dos vídeos produzidos pela Agência África para promover o projeto Isso Muda o Mundo, do Banco Itaú, fazem o espectador prestar maior atenção aos depoimentos e às reações das crianças em sua interação com a cultura e a arte, do que propriamente no logotipo de assinatura. 


\section{Eu consumo, tu consomes, mas... quem compra?}

Ao seguirmos uma metodologia desconstrutiva para tratar do tema do consumo infantil, a primeira proposição colocada aos meus alunos é, a partir de um excerto de Gisela Taschner (2009), discutir o que é consumo, em especial, o consumo conspícuo. Ao defender o desejo histórico pelo supérfluo - ou seja, entre outros bens, os de novidade, e não necessariamente de luxo - seja por aquisição via compra ou por apropriação simbólica ${ }^{14}$, a socióloga reivindica o direito ao consumo como "passaporte para a obtenção da cidadania" (TASCHNER, 2009, p. 19) e o direito a uma educação nesse sentido. Pois todos, de alguma forma, participam da cultura do consumo, independente do poder econômico ou do custo capital de um dado produto, uma vez que: "Há uma dimensão de lazer em algumas formas de consumo [...]. Há também uma dimensão de consumo no lazer [...]." (TASCHNER, 2009, p. 77).

Ao referir-se aos órgãos que procuram regular o consumo por via da compra, é preciso, segundo a análise dessa autora, levar em consideração a ambiguidade que caracteriza tal comportamento: proteger o consumidor não deve significar o impedimento ao consumo (pois trata-se de um direito assim como o de lazer - quando o cidadão decide o que faz em seu tempo livre), mas, sim, informá-lo, para que possa exercê-lo de modo responsável, crítico e com liberdade de escolha.

Infelizmente, a ausência de uma visão esclarecida e aprofundada das relações entre mercado, publicidade e infância, vem se traduzindo numa interdição ao direito que toda criança tem, como cidadã participativa da sociocultura, de ser educada para o consumo sábio e consciente. A regulamentação sobre a publicidade para a infância, assim, além de impedir sua

\footnotetext{
${ }^{14}$ A partir do que coloca Taschner sobre a cultura do consumo, afirmando-a como aquela que se dá 'a partir do momento em que 'não os bens', mas a 'imagem' desses bens se torna acessível a todos na sociedade" (TASCHNER, 2009, p. 52), posso inferir que mesmo a aquisição temporária, por via do empréstimo, pode ser considerada como tal. Embora a autora denuncie a exclusão em relação ao poder aquisitivo, ela coloca todo cidadão como participante da cultura de consumo. Assim, também consome o sujeito que usufrui da biblioteca por empréstimo de livros, o internauta que, ao acessar sites e portais, consome informação ou o flâneur (transeunte ocioso) que passeia pelos shoppings apenas para apreciar as vitrines e o visitante de um museu ou galeria que "consome", através da apreciação, a obra artística.
} 
expressão cidadã, a vulnerabiliza como consumidora. Ao posicionar-se contra o apelo estético da cultura midiática, desvia-se do problema e isenta o adulto educador da responsabilidade de formar a criança para exercer seu direito de cidadã.

A regulamentação do CONANDA seria, conforme Taschner, inútil: ela não pode reprimir o consumo conspícuo, que se encontra desde sempre em nossa cultura, simplesmente interditando a criança o prazer lúdico de assistir aos intervalos comerciais, quando e se o quiser. E a educação, ao tomar superficialmente o tema do consumo infantil posicionando a criança como vítima indefesa da publicidade, deveria antes perguntar-se quais as forças que de fato sustentam tal imagem maniqueísta, ou a quem interessa sonegar a educação para o consumo conspícuo, cujo impulso poderia potencializar, inclusive, a apreciação lúdica e prazerosa de objetos simbólicos, estando as artes entre eles.

Como complementação, proponho aos meus alunos a leitura de um excerto de Jurandir Freire Costa, para esclarecer a diferença entre consumo e comprismo. O psicanalista desconstrói a visão de que "somos aquilo que a produção econômica nos faz ser" (COSTA, 2005, p. 17). Para o psicanalista, em convergência a Taschner, o ser humano aprendeu a associar consumo à felicidade e ao bem-estar. Essa pulsão, ou desejo, enraíza-se numa prática que o antecede e não deriva, portanto, de um sistema econômico. Assim, não é a industrialização de objetos e o consequente aumento de ofertas de um dado produto o motivador de uma prática consumista, mas é a insatisfação do sujeito que adjunta à ação de consumir a necessidade de comprar, principalmente o descartável, pois o que se deseja é a reprodução do ato pelo fim em si, sem levar em conta, inclusive, o valor - simbólico ou monetário - do objeto que se compra. Em outras palavras, a publicidade não será motivadora do comprismo desenfreado, a não ser para aquele sujeito já compulsivo. A subjetividade compulsiva não é consumista (aquela que, por meio da compra, visa suprir uma necessidade, seja ela conspícua ou não), mas comprista (aquela que faz da compra um fim em si mesmo). A publicidade não induz o sujeito à compra de um 
dado produto, mas potencializa, isto sim, através de uma retórica sedutora que combina informação a dados estéticos, o consumo do objeto divulgado ${ }^{15}$.

Crianças são consumistas conspícuas, pois carregam consigo o desejo que todos nós carregamos, isto é, o de valorizar as nossas identidades socioculturais agregando a estas valores simbólicos. Mas, aprioristicamente, não podem ser compristas ${ }^{16}$, pois não são empoderadas para o uso do capital. Contudo, afirma-se que elas podem induzir os adultos à compra. Ao assistir o documentário A criança é a alma do negócio (RENNER, 2008) o que mais dói, a meu ver, não são os desejos de consumo revelados pelas crianças, mas o grau de infelicidade dos adultos que vitimam os infantes em nome da necessidade de solucionar seus recalques, suas frustrações, através do comprismo, com a desculpa de que agem em nome da felicidade da criança. Todo infante tem o direito de desejar e de consumir, enquanto cidadão em nossa cultura, de forma conspícua. Já a compulsão pela compra dificilmente será resolvida pela pedagogia infantil ou por resoluções protecionistas e impositivas - sobretudo, por um ensino de artes que, ao deixar de verificar o entrelaçamento entre os fenômenos de mercado, artísticos e educacionais, interpreta tudo a partir da superfície da imagem.

Mais profundamente, concordarei por fim com Sibilia quando ela adverte que o conflito entre a escola e os novos modos de organização e veiculação da cultura e da arte é uma das maiores causas da crise que assola as instituições de ensino. Enquanto a pedagogia, ainda apoiada num pensamento kantiano, insiste em formar o cidadão passivo, produtor ou operário à moda antiga, a

\footnotetext{
${ }^{15}$ Exemplo: as crianças veem um dado brinquedo num comercial de TV, mas se satisfazem com uma versão mais barata do mesmo brinquedo. A ostentação do brinquedo infantil é um desejo do adulto, não da criança, cujo único desejo é fazer parte do universo imaginário e estético proposto pela cultura midiática, desejo esse que pode ser satisfeito de muitas outras maneiras. E se em todas se requer um ato de compra, é porque em todo consumo contemporâneo há um valor monetário irremediavelmente embutido, mesmo em produtos caseiros ou artesanais.

${ }^{16}$ Claro que aqui se fala de uma criança em geral. Crianças recebem mesada - ainda que dificilmente entrem numa loja sozinhas - ou ganham dinheiro por meio de trabalho ilegal ou informal. O comprismo infantil — quando a criança toma posse do dinheiro e tem autonomia para comprar - merece, sim, um estudo mais aprofundado, que não cabe neste artigo. Nesse sentido, é importante mencionar que o Banco Itaú promoveu uma campanha para a educação econômica desde as idades iniciais, cobrindo a lacuna deixada pelos setores da educação. A campanha, cujo tema é o uso consciente do dinheiro, é veiculada livremente no YouTube: $<$ https://www.youtube.com/watch?v=lbxsh7kTOoU $>$.
} 
sociedade organizada em rede e fundamentada numa economia estética requer das novas gerações maior proatividade e autonomia. Tais qualidades só poderão ser potencializadas positivamente se, junto à diluição dos muros que entricheiram as salas de aula contra os fenômenos culturais midiáticos contemporâneos, estabelecer-se uma relação de confiança, flexibilidade e diálogo aberto entre os sujeitos em educação. Dentro disso, é preciso, juntamente com a aceitação dos demais lugares da cultura e da arte, aceitar integrar os modos de perceber, desejar e de agir da juventude e da infância a pedagogias promotoras de uma consciência responsável de si e do outro.

\section{Referências}

BENJAMIN, Walter. Passagens. São Paulo: Imprensa oficial, 2009.

BENJAMIN, Walter. Rua de mão única: infância berlinense: 1900. Belo Horizonte: Autêntica, 2013.

BOURDIEU, Pierre. A economia das trocas simbólicas. São Paulo: Perspectiva, 2011.

COSTA, Jurandir Freire. O vestígio e a aura. Rio de Janeiro: Garamond, 2005.

DRUCKER, Johanna. Art. In: MITCHELL, William J. T.; HANSEN, Mark (Eds.). Critical terms of media studies. Kindle Edition. Chicago: University of Chicago, 2010, p. 249-456.

EAGLETON, Terry. A ideologia da estética. Rio de Janeiro: Jorge Zahar, 1993.

FUNDAÇÃO ALANA. Site. Disponível em: <http://alana.org.br>. Acesso: 20 abr. 2015.

HAUSER, Arnold. História social da literatura e da arte, v 1 e 2. São Paulo: Mestre Jou, 1982.

LIPOVETSKY, Gilles; SERROY, Jean. A estetização do mundo: viver na era do capitalismo artista. São Paulo: Companhia das Letras, 2013.

MARANHÃO, Jorge. A arte da publicidade: estética, crítica e kitsch. Campinas: Papirus, 1988.

MARTINS, Raimundo (Org.). Visualidades e educação. Goiânia: Funape, 2008.

MASTROBERTI, Paula. O livro como objeto predisposto à interdisciplinaridade. Revista Gearte, v. 1, n. 2, p. 167-181, 2014. Disponível em: <http://www.seer.ufrgs.br/index.php/gearte/article/ view/47928/31270>. Acesso em: 19 abr. 2015.

MEDEIROS, Paulo et al. Isso muda o mundo. Agência África, 2013.

MITCHELL, William J. T.; HANSEN, Mark (Eds.). Critical terms of media studies. Kindle Edition. Chicago: University of Chicago, 2010.

NUNES, Ana Luiza Ruschel. Trabalho, arte e educação: formação humana e prática pedagógica. Santa Maria: UFSM, 2004.

RAY, Erh; GUANAES, Nizan. Mamíferos. Agência DM9DDB, 1996.

RENNER, Estela (Dir.). A criança é a alma do negócio. Marcos Nisti e Maria Farinha Produções. Projeto Criança e Consumo do Instituto Alana, São Paulo, 2008. Disponível em: <http://alana.org.br>. Acesso: 20 abr. 2015.

SIBILIA, Paula. Redes ou paredes: a escola em tempos de dispersão. Rio de Janeiro: Contraponto, 2012.

START ANIMA. Aquarela. Filme publicitário. Agência FCB, 1983. Disponível em: <https://www.youtube.com/watch?v=LP55uXmyN7A> . Acesso: 20 abri. 2015. 
TASCHNER, Gisela. Cultura, consumo e cidadania. São Paulo: Edusc, 2009.

\section{Paula Mastroberti}

É artista plástica, escritora, ilustradora e quadrinista premiada. Trabalhou como cenarista e diretora de arte em cinema de animação durante quinze anos e dedicou-se à publicidade por dois anos, como assistente de arte free-lancer. É graduada no Bacharelado de Artes Plásticas pela Universidade Federal do Rio Grande do Sul (UFRGS), mestre e doutora em Teoria da Literatura pela Pontifícia Universidade Católica do Rio Grande do Sul (PUCRS). Atualmente é professora do Instituto de Artes da UFRGS.

E-mail: paulamastroberti@gmail.com

Currículo: http://lattes.cnpq.br/2785011594553498 